\title{
El papel de la maestra en la promoción de dos competencias de la inteligencia emocional de niñas y niños de quinto grado
}

\author{
Teacher's Role in the Promotion of Two Emotional Intelligence Competencies in \\ Fifth-Grade Children
}

\author{
Ruth Villanueva Barbarán \\ División de Educación para el Trabajo \\ Centro de Investigación y Docencia en Educación \\ Universidad Nacional \\ Heredia, Costa Rica \\ rvillanu@una.ac.cr \\ Grettel Valenciano Canet $^{2}$ \\ Escuela de Orientación y Educación Especial \\ Facultad de Educación \\ Universidad de Costa Rica \\ San José, Costa Rica \\ gvalencianoc@gmail.com
}

Recibido 30 de marzo de 2012 • Corregido 17 de setiembre de 2012 • Aceptado 07 de noviembre de 2012

Resumen. Este artículo resume los resultados de una investigación cualitativa cuyo objetivo es analizar el papel de la maestra en la promoción del conocimiento y el manejo de las propias emociones de un grupo de niñas y niños de un quinto grado escolar como competencias de la inteligencia emocional. Este estudio resultó relevante en la medida en que, desde el ámbito de la psicopedagogía, se propone romper con el papel tradicional del personal docente centrado exclusivamente en la transmisión de conocimientos, que ha dejado de lado la dimensión de apoyo emocional que tanto necesitan las personas. Se evidenció en las niñas y los niños un pobre vocabulario emocional, dificultad para identificar algunas emociones y para diferenciarlas. Esto se refleja en una limitación para tomar conciencia de sus propias emociones y en la dificultad para controlarlas. Por otra parte, se demuestra la importancia de potenciar habilidades emocionales del estudiantado, como una tarea primordial en los centros educativos, en los cuales la persona docente desempeña un papel fundamental como modelo y promotora de la inteligencia emocional.

Palabras claves. Inteligencia emocional, conocimiento de las propias emociones, manejo de las emociones, alfabetización emocional, docente, educación emocional.

Máster en Psicopedagogía, Universidad Estatal a Distancia. Bachiller y Licenciada en Ciencias de la Educación con énfasis en Orientación, Universidad de Costa Rica. Integrante del equipo del proyecto de extensión Orientando Familias, investigadora y académica de la División de Educación para el Trabajo, Universidad Nacional.

2 Máster en Psicopedagogía, Universidad Estatal a Distancia. Licenciada en Psicopedagogía, Universidad Nacional. Bachiller en Ciencias de la Educación con énfasis en Orientación, Universidad de Costa Rica. Profesora de la Escuela de Orientación y Educación Especial, Universidad de Costa Rica. 


\begin{abstract}
This paper presents the results of a qualitative study aimed at analyzing the teacher's role in promoting awareness and management of emotions in fifth-graders, as competencies of emotional intelligence. This resulted in a very significant study since, from the psychopedagogic perspective, it aims at breaking with the traditional role of teachers exclusively focused on transmitting knowledge, leaving aside the much-needed emotional support. Children demonstrated a poor vocabulary, as well as difficulty to identify some emotions and differentiate between them. This means a limitation for children to be aware of their own emotions and to control them. As a conclusion, it is important to maximize the emotional capacities of students; it should be a primary task in the education centers, where teachers play a key role as a model and as a promoter of emotional intelligence.
\end{abstract}

Keywords. Emotional intelligence, awareness of self-emotions, emotional management, emotional literacy, teacher, emotional education.

Potenciar las competencias del estudiantado para una inteligencia emocional es, actualmente, una labor indispensable en los centros educativos, debido a que la sociedad de hoy enfrenta serios problemas de violencia, estrés, depresión, crímenes, suicidios, drogadicción, entre otros. Dichas situaciones son el reflejo de un analfabetismo emocional, el cual es entendido como la incapacidad de manejar nuestras propias emociones y las de otros.

Goleman (1995) se refiere a los elevados costos del analfabetismo emocional aportando datos estadísticos de la incidencia de crímenes, violencia, arrestos, uso de armas de fuego, suicidios, inseguridad ciudadana, la depresión, la ansiedad, el estrés, desórdenes en la comida (bulimia, anorexia), drogas, alcoholismo, conducción temeraria y otros. Todos estos datos tienen que ver con el analfabetismo emocional.

Seconsidera que las situaciones mencionadas no solo deben ser tratadas terapéuticamente, sino que se deben tomar medidas preventivas al respecto. Desde luego, esto involucra al sistema educativo, por lo que Bisquerra (2001) propone la educación emocional como respuesta educativa a un déficit en el manejo de las emociones. Lo que se pretende es prevenir el analfabetismo emocional a través del sistema educativo formal.

Hoy se sabe que "los fines de la educación en competencias son el pleno desarrollo de la persona" (Zabala y Arnau, 2007, p. 65). El desarrollo involucra entre otros aspectos: el desarrollo cognitivo y el desarrollo emocional. Este último se relaciona con la inteligencia emocional $y$, por lo tanto, con la educación emocional, la cual se piensa debe incorporarse dentro del currículo escolar.

Esta necesidad de educación emocional tiene como objetivo un mejor conocimiento de las emociones, la capacidad para controlar las mismas, fomentar una actitud positiva ante la vida y otros.

Begoña (2003) señala que, dado que cada vez más niños y niñas no reciben en la vida familiar un apoyo seguro para transitar por la vida, y que muchos padres y madres de familia no pueden ser modelos de inteligencia emocional para sus hijos o hijas, las escuelas pasan a ser el único lugar hacia donde pueden volverse las comunidades en busca de pautas para superar 
las deficiencias de los niños y las niñas en la aptitud social y emocional. Esto no significa que la escuela, por sí sola, pueda suplantar a todas las instituciones sociales; pero, desde el momento en que prácticamente todos los niños y las niñas concurren a la escuela, esta ofrece un ámbito donde se les puede brindar lecciones de vida que no podrían recibir en ninguna otra parte. Dicha tarea exige dos cambios importantes: primero, que el profesorado comprenda que educar es mucho más importante que transmitir conocimientos y segundo, que la familia y los miembros de la comunidad se involucren más profundamente con la actividad escolar.

Las personas profesionales de la educación se encuentran actualmente ante el reto de alfabetizar emocionalmente. Sin embargo, por la escasa formación en este campo, muchas de ellas no están preparadas para poder abordarlo. Motivo por el cual se hace imperativo una capacitación constante.

Según Bisquerra (2001), las repercusiones de la educación emocional pueden dejarse sentir en las relaciones interpersonales, en el clima de clase, en la disciplina, en el rendimiento académico y en otros. Desde esta perspectiva, se la puede considerar también una estrategia de prevención de comportamientos inadecuados de las personas.

Si se quiere una educación que prepare para la vida, es necesario atender al desarrollo emocional de las personas, como complemento indispensable del desarrollo cognitivo. En este sentido, las competencias emocionales son competencias básicas para la vida. Responder esta necesidad implica la implementación de programas y proyectos de educación emocional.

Dentro de la línea de la investigación cualitativa, y en busca de rescatar el papel que desempeña la persona docente como modelo y promotora de la inteligencia emocional del estudiantado, se lleva a cabo un estudio en el que cobra gran relevancia el conocimiento, referido este último a la autoconsciencia emocional y al manejo de las propias emociones que poseen las niñas y los niños como competencias de la inteligencia emocional.

El propósito de este artículo es presentar los resultados de la investigación, de tipo cualitativo interpretativo, realizada en un estudio de caso con una docente y su respectivo grupo de veintiséis estudiantes que cursan el quinto grado escolar de una escuela pública urbana. Se toman como base las expresiones verbales y no verbales, situaciones, percepciones, interacciones y comportamientos observados para dar respuesta a la siguiente interrogante: ¿Promueve la maestra el conocimiento y manejo de las propias emociones de sus estudiantes mientras desarrolla el currículo escolar?

\section{Aspectos teóricos}

El sustento teórico que orienta esta investigación está fundamentado en la teoría sobre la inteligencia emocional desarrollada por varios autores como (Goleman, 1995; Salovey y Mayer, citados por Casas, 2001). 
URL: http://www.una.ac.cr/educare

La inteligencia emocional se ha entendido como un conjunto de competencias que implican las emociones (Goleman, 1995). Los diferentes teóricos han expresado sus propias definiciones. A continuación se mencionan algunas de ellas:

Un subconjunto de la inteligencia social que comprende la capacidad de controlar los sentimientos y emociones propios así como los de los demás, de discriminar entre ellos y utilizar esta información para guiar nuestro pensamiento y nuestras acciones. (Salovey y Mayer, citados por Casas, 2001, p. 3)

Las personas que se consideran con una alta inteligencia emocional han sido relacionadas con una adecuada autoestima, estado de ánimo positivo, sentimientos de bienestar emocional y una mejor perspectiva de vida. Para lograr esta condición es necesario el desarrollo de ciertas competencias o habilidades, las cuales han sido expuestas por los teóricos de la inteligencia emocional.

La teoría de la inteligencia emocional, según Goleman (1995), involucra ciertas competencias o habilidades idóneas para que las personas puedan llegar a tener una vida más plena. Tales competencias son: conocimiento de las propias emociones, capacidad de controlar las emociones, capacidad de motivarse a sí mismo, reconocimiento de las emociones ajenas y manejo de las relaciones.

El concepto de competencia se refiere al dominio de un conjunto de habilidades. Le Boterf, citado por Bisquerra (2002), considera que la competencia resulta de un saber actuar y es necesario poder y querer actuar para que esta se construya.

Específicamente en esta investigación se analizaron dos competencias: Conocimiento de las propias emociones o autoconciencia y manejo de las emociones o autorregulación.

\section{Conocimiento de las propias emociones o autoconciencia:}

Para la comprensión del conocimiento de las propias emociones es importante revisar primero el concepto de emoción.

La definición de emoción está relacionada con impulsos instantáneos que predisponen a la persona a una determinada actuación. La palabra emoción se deriva del latín motere (moverse) y se refiere a un estado psicológico caracterizado por una conmoción orgánica, producto de sentimientos, ideas o recuerdos, y que pueden expresarse en gestos, actitudes, risa, llanto, etc. (Cortese, s. f.).

En relación con lo anterior, Goleman (1995) opina que las emociones poseen un poder extraordinario en el ser humano, son tendencias para actuar. Agrega que las personas poseen una mente racional y otra emocional, una que piensa y otra que siente; las cuales, en su interacción, forman la vida mental de un individuo. La emoción juega un papel importante 
en la vida humana. En algunas situaciones, predomina el corazón sobre la cabeza. Cuando se trata de enfrentar momentos difíciles, muchas veces el intelecto o la mente racional no es suficiente, entonces, es cuando la mente emocional toma el liderazgo, como por ejemplo, el instinto de una madre por salvar a su hijo o hija la puede llevar a ignorar sus conocimientos de supervivencia personal y ponerse en riesgo, con tal de salvar a su pequeño o pequeña.

Las emociones no solo son impulsos en reacciones inmediatas, también son importantes motivadoras para conductas futuras, pues pueden trascender en el tiempo. De esta forma, son capaces de energizar la conducta, motivando planes, metas, necesidades fisiológicas, entre otros.

De acuerdo con Portugá y Cruz (1999), las emociones poseen tres componentes:

- Pensamientos y apreciaciones cognitivas. Se refieren al análisis subjetivo de las experiencias que un individuo posee y que le han dado nombre a las diferentes emociones.

- Cambios fisiológicos. Incluyen los comportamientos de los sujetos ante las diferentes emociones. Por ejemplo: con la ira, la sangre fluye a las manos, el ritmo cardíaco se eleva y la hormona de la adrenalina aumenta.

- Comportamientos o tendencias a la acción. Influido por los cambios fisiológicos, el cuerpo genera un ritmo de energía capaz de originar una acción específica. En el caso de la ira puede ser una acción violenta.

Las emociones se han caracterizado de diversas formas y existen múltiples combinaciones. Goleman (1995) presenta la siguiente clasificación en donde propone una titular y las que de ella se derivan:

Ira: furia, ultraje, resentimiento, cólera, exasperación, indignación, fastidio, irritabilidad, hostilidad, el extremo de violencia y odio patológico.

Tristeza: pesar, melancolía, pesimismo, autocompasión, soledad, abatimiento y, en casos extremos, depresión grave.

Temor: ansiedad, nerviosismo, preocupación, consternación, inquietud, cautela, incertidumbre, miedo, pavor, en el nivel extremo fobia y pánico.

Placer: felicidad, alegría, alivio, contento, dicha, deleite, diversión, orgullo, placer sexual, estremecimiento, gratificación, satisfacción, euforia, éxtasis y en el extremo manía. Amor, aceptación, confianza, amabilidad, afinidad, adoración.

Sorpresa: conmoción, asombro, desconcierto.

Disgusto: desdén, desprecio, aborrecimiento, aversión, disgusto, repulsión. (pp. 331-332) 
Otros autores como Rizo (1997) organizan las emociones en primarias y secundarias. Las primarias son innatas, se nace con ellas, son naturales, no aprendidas. Cumplen una función adaptativa, no son duraderas y se agotan a sí mismas. Su duración se limita a cumplir con su función. Algunas de ellas son el dolor, el miedo, la tristeza, y la alegría.

Las emociones secundarias son aquellas aprendidas, no parecieran cumplir una función biológica adaptativa; pero, si son bien administradas, podrían llegar a ser muy útiles. Estas, según (Rizo, 1997), "(...) son defensivas o manifestaciones de un problema no resuelto, y casi siempre implican debilitamiento del yo. Sufrimiento, ansiedad, depresión, ira y restricciónapego, son algunas de las más significativas. A diferencia de las primarias, no se agotan a sí mismas y pueden permanecer por años o toda la vida (...) (p. 23).

El conocimiento de las propias emociones o autoconciencia se refiere, de acuerdo con Goleman (1995), a la capacidad de reconocer las emociones que se experimentan, así como la intensidad en que se están viviendo, de esta manera se puede saber cuánto está afectando o no. Esta habilidad es de mucha importancia, pues es la base para las otras. No se puede controlar un sentimiento, moderar u ordenar lo que no se logra identificar o, al menos, nombrar. El manejo de las emociones propias puede ser adquirido mediante la auto-observación y la observación de aquellos que rodea a la persona. Implica la comprensión de la diferencia entre pensamientos, acciones y emociones, evaluar su intensidad, reconocerlas y utilizar el lenguaje -a nivel verbal y no verbal- acorde con la emoción.

Goleman (1995), por lo tanto, pone de relieve la importancia de conocer las propias emociones. Así, tener conciencia de ellas es la competencia emocional fundamental sobre la cual se construye el autocontrol. Por esto es necesario distinguir entre conocer las propias emociones y el controlarlas. En la medida en que la persona percibe que tiene emociones negativas que le desestabilizan tiende a actuar para cambiarlas. Es decir, la toma de conciencia y el manejo de emociones, para este autor, tienden a ser dos caras de la misma moneda.

Para controlar una emoción, un elemento necesario es el reconocimiento de esta. Por ejemplo, reconocer que se está de mal humor es el primer paso para intentar cambiarlo. Sin embargo, hay que dar el paso siguiente: controlarlo; pero en este momento, muchas veces se interponen barreras y obstáculos emocionales que también conviene reconocer. Los bloqueos emocionales, en ocasiones, nos impiden manifestarnos con naturalidad ante ciertas personas.

Para Bisquerra (2001) carecer de palabras para denominar las emociones impide tomar conciencia de ellas. Y, por consiguiente, la imposibilidad de controlarlas. De esto se deriva la importancia de potenciar el desarrollo del vocabulario emocional desde el sistema educativo. Si podemos poner palabras a lo que sentimos, estamos en el buen camino para desarrollar la inteligencia emocional.

Las emociones tienen un papel importante en la vida de las personas. El mundo emocional de un individuo va tomando su forma desde sus primeros años de vida. La confianza en uno mismo, el autocontrol, la apertura frente a lo nuevo, la capacidad de empatía, el saber disfrutar 
del contacto con otras personas, son capacidades elementales que los niños y las niñas van construyendo en el seno de su familia. Son la base del posterior desarrollo emocional.

\section{Manejo de las emociones o autorregulación}

El manejo de las emociones implica, según Goleman (1995), saber controlar los propios estados de ánimo, impulsos y recursos; saber cuándo y cómo expresarlos, así como el posible efecto que puedan causar en los demás. No podemos elegir nuestras emociones, desconectarlas o evitarlas, pero sí está dentro de nuestro poder regular nuestras reacciones y el comportamiento que se derive. La manera en cómo manejemos nuestras emociones va a depender de nuestra inteligencia emocional. Es muy importante no confundir la autorregulación, manejo, control o cualquier otra forma en que llamemos esta habilidad con la represión.

Algunos componentes importantes de la habilidad de la autorregulación son: tolerancia a la frustración, manejo de la ira, capacidad para retrasar gratificaciones, tipo de afrontamiento en situaciones de riesgo, desarrollo de la empatía, entre otros. Algunas técnicas que favorecen esta habilidad son: diálogo interno, control del estrés (relajación), autoafirmaciones positivas, asertividad, reestructuración cognitiva, atribución casual, imaginación emotiva, entre otros.

Según el mencionado autor, las competencias emocionales relacionadas con la autorregulación son:

- Autocontrol: mantener vigilancia sobre las emociones perturbadoras e impulsos.

- Confiabilidad: mantener estándares adecuados de integridad y honestidad.

- Conciencia: asumir la responsabilidad del propio desempeño.

- Adaptabilidad: flexibilidad adecuada ante situaciones de cambio.

- Innovación: sentirse cómodo, no amenazado, ante nuevas ideas, informaciones o situaciones.

Bisquerra (2001) considera que desde la perspectiva de la educación emocional lo que interesa es el control de las emociones. Pero no se puede perder de vista una concepción más integradora de la persona humana, desde la cual el control emocional incide en el control del comportamiento y del pensamiento, así como de los impulsos fisiológicos. Es desde esta perspectiva integradora que vamos a referirnos al autocontrol, aunque en algunos casos podamos mencionar específicamente el "control emocional".

El adecuado manejo de las emociones traerá múltiples beneficios a la persona. Portugá y Cruz (1999) señalan que mejorar la inteligencia emocional traerá beneficios tales como: 
URL: http://www.una.ac.cr/educare

- Mejor habilidad de solución de problemas.

- Mayor tolerancia a la frustración: personas menos agresivas.

- Disminución de la ansiedad y un mejor manejo del estrés.

- Habilidades sociales asertivas: incremento de la habilidad de trabajo en equipo.

- Reflexión antes de actuar: mejor manejo del impulso.

Además se podría mencionar que la persona se siente más a gusto consigo misma y en el entorno en que se desenvuelve. Un adecuado manejo de nuestras emociones nos permite llevar una vida más plena y más llena de significado personal.

\section{El papel del maestro y la maestra en el desarrollo de la inteligencia emocional del estudiantado}

Para López y González (2005), los centros educativos son la segunda sociedad a la cual pertenece el estudiantado. En la medida del cambio de la estructura familiar y social, en el cual se exige, cada vez más, la figura de la madre trabajadora, las instituciones escolares son introducidas más tempranamente en la vida del niño y de la niña. Las jornadas escolares son estructuradas de tal forma que, la mayoría del tiempo activo, los alumnos y las alumnas permanecen bajo la influencia de los docentes y las docentes. Estos hechos refuerzan la necesidad de evaluar cuidadosamente no solo los programas académicos como tales, sino también la calidad del soporte que proporcionan en el desarrollo de la inteligencia emocional.

Según las autoras mencionadas, las primeras figuras de autoridad son el padre y la madre, posteriormente se introducen el personal docente y personal educativo como una nueva instancia de figuras de poder. Cuando los niños y las niñas son orientados y asesorados por estas personas que les proporcionan un adecuado modelo en el manejo y control de las emociones, empiezan a imitar este comportamiento.

Así, uno de los aspectos necesarios para promover el desarrollo de la inteligencia emocional en los estudiantes y las estudiantes consiste en que el docente y la docente desarrollen también su propia inteligencia emocional. El maestro o la maestra son modelos para los alumnos y las alumnas, es decir, enseñan en su propia práctica pedagógica su personalidad.

Para Begoña (2003), educar con inteligencia emocional implica que el profesorado sepa identificar sus sentimientos y emociones, sepa controlar su expresión, no reprimirla sino ofrecer modelos adecuados de expresión, sobre todo cuando se trata de emociones negativas que suelen ser más difíciles de comunicar de una forma respetuosa. 
El profesorado debe comprender que educar es mucho más que transmitir conocimientos. Álvarez (2001, p. 44) considera que "(...) el rol tradicional del profesor, centrado en la transmisión de conocimientos, está cambiando. La obsolescencia del conocimiento y las nuevas tecnologías conllevan a que la persona adquiera conocimientos en el momento que los necesite. En este marco, la dimensión de apoyo emocional del profesorado pasa a ser esencial". Entonces, uno de los requisitos para que el profesor y la profesora asuman su tarea de desarrollar la inteligencia emocional de los alumnos y las alumnas es que se comprometa a desarrollar la propia.

Respecto al uso de la propia inteligencia emocional de los educadores y las educadoras, Begoña (2003) sugiere que estos deberán ser capaces de:

- Expresar adecuadamente sus sentimientos en la relación con los alumnos y las alumnas.

- Utilizar la metodología de planificación en función de metas y de resolución de problemas.

- Poner en práctica estrategias de automotivación.

- Controlar sus estados de ánimo negativos y gestionar adecuadamente sus emociones.

- Manifestar su empatía y capacidad de escucha.

- Desarrollar conductas asertivas, manejando adecuadamente los conflictos que se produzcan en el aula.

Por lo tanto, la promoción y desarrollo de la inteligencia emocional en el aula, tanto del docente como del discente, debe darse de modo coordinado de manera tal que el propio proceso potenciará un respeto mutuo de las propias emociones, lo que supone, necesariamente, saber cómo nos sentimos y ser capaces de comunicar adecuadamente nuestras sensaciones, facilitando, de este modo, la creación de ambientes positivos de aprendizaje, donde las personas involucradas sientan la libertad de expresar lo que sienten de manera adecuada.

La inteligencia emocional del profesor constituye una de las variables que mejor explica la creación de un aula emocionalmente inteligente. Además, esta parece depender de cómo gestiona sus propias emociones, especialmente las de naturaleza negativa. Quien ejerce como docente no debería negar sus emociones negativas, sino ser capaz de expresarlas de un modo saludable dentro de la comunidad que construye con su estudiantado.

Algunas de las claves prácticas relacionadas con esta gestión emocional en el aula y la misión del educador, según López y González (2005), son: 
URL: http://www.una.ac.cr/educare

- Dominar sus propias respuestas emocionales, ya que su conducta incide más en el comportamiento de sus estudiantes que los regaños y sermones.

- Enseñar a los alumnos y a las alumnas a controlarse y a gestionar sus emociones, mostrándoles que la única respuesta no es el enfado cuando algo sale mal o el engreimiento cuando sale bien.

- Ayudar a que el grupo estudiantil se aprecie y acepte ya que es fundamental para desarrollar la confianza en sí mismo.

- Aprender a conocer a los discentes y las discentes, ya que esto permite dirigir, de manera puntual y efectiva, la disciplina y la formación de valores.

- Desarrollar modelos de reacción que reduzcan el mal comportamiento.

- Ser consistentes en las reglas y límites que se determinen como necesarios para la buena educación de los niños y de las niñas.

- Ser consecuentes con las acciones de manera que se genere confianza y credibilidad en los niños y las niñas.

- Anticipar problemas y definir estrategias permite manejar más efectivamente los conflictos.

- No dejar que el mal comportamiento reste el disfrute que constituye apreciar al estudiantado, inclusive cuando no se comporte como se espera.

- Ser firmes, pero positivos.

- Estar dispuestos a cambiar. Siempre habrá cosas por mejorar y aspectos nuevos por aprender, incluso de los mismos estudiantes.

- Ser responsable de sus propias emociones, no culpar a los alumnos y a las alumnas de las mismas. Esto implica un manejo adecuado de las emociones.

Así, todo educador o educadora debería prestar atención a la alfabetización emocional de su estudiantado, procurar ayudar a mirar en su interior a menudo para descubrir cuáles son sus estados emocionales y por qué son provocados. Evidentemente, la educación de las emociones requiere una formación inicial; pero también una formación permanente. Este tipo de educación es importante, porque puede convertirse en una prevención inespecífica, como por ejemplo, prevención del estrés, de la depresión, de los conflictos interpersonales y, a la vez, potencia el desarrollo personal y social.

Se hace necesario que el estudiantado comprenda que las emociones son una parte fundamental del ser humano, pues determinan el comportamiento y se manifiestan a través del ajuste social, el bienestar y la salud mental. 
Salovey y Sluyter, citados por Colom (1998), señalan que, por lo que a la práctica docente se refiere, la promoción de la inteligencia emocional debe llevarse a efecto de un modo coordinado con la promoción de las demás capacidades de los estudiantes y las estudiantes.

Por lo tanto, la inteligencia emocional debe promoverse a través de la práctica pedagógica: El personal docente es un agente promotor del conocimiento y manejo de las propias emociones de sus educandos. Si los docentes y las docentes logran impartir una educación emocional acertada, podrán conducir al estudiantado a orientar sus propios sentimientos o los de otros de manera sana y positiva.

\section{Estrategia metodológica}

Dado que lo que interesa es interpretar las percepciones, actitudes, intereses, interacciones y concepciones que se establecen entre la docente y sus estudiantes, se utilizó el enfoque cualitativo, el cual procura comprender la realidad de las personas desde sus propias perspectivas, empleando sus palabras y conductas. Taylor y Bodgan (1992, p. 20) afirman que "(...) produce datos descriptivos: las propias palabras de las personas, habladas y escritas y la conducta observable (...)".

Dentro de este enfoque cualitativo, se siguió el método interpretativo.

El proceso metodológico se llevó a cabo siguiendo las siguientes etapas del modelo de Rodríguez, Gil y García (1996):

Etapa preparatoria: Se realizó la revisión bibliográfica sobre la inteligencia emocional y se explicitó el problema de investigación. Se seleccionó la población participante, la cual está conformada por una maestra y su grupo de veintiséis estudiantes de quinto grado escolar, de una escuela pública, urbana, en la provincia de Heredia.

Etapa de trabajo de campo: La recolección de la información fue realizada en un año con las siguientes técnicas: la entrevista cualitativa semi-estructurada, la observación participante, grupos focales y un cuestionario.

Etapa de análisis de los resultados: Para el procesamiento y análisis de la información se utilizó el diseño de Taylor y Bogdan (1992), el cual consta de tres fases: descubrimiento en progreso, codificación (elaboración de categorías de análisis) y la relativización de los datos, que incluye la triangulación mediante diversas fuentes: la maestra, el estudiantado y lo observado por las investigadoras.

Etapa informativa: Se construyó el texto respondiendo la pregunta de investigación. 
URL: http://www.una.ac.cr/educare

\section{Análisis de resultados}

Este apartado recoge las expresiones, observaciones y comentarios brindados por las personas participantes del estudio, en formato de citas etnográficas. Además, se presenta la triangulación de esas experiencias con aportes teóricos respecto a los temas que aborda la pregunta de investigación: ¿Promueve la maestra el conocimiento y manejo de las propias emociones de sus estudiantes mientras desarrolla el currículo escolar?

\section{El conocimiento de las propias emociones del estudiantado de quinto grado}

\section{Concepto de emoción o emociones que poseen:}

Los teóricos de la inteligencia emocional consideran importante trabajar el concepto de emoción en el desarrollo de las habilidades para la inteligencia emocional. Núñez (2005) señala que, para trabajar con las niñas y los niños el conocimiento de las emociones, es necesario explicarles y enseñarles lo que es una emoción. De manera psicopedagógica se debe partir primero de los conocimientos previos que ellas y ellos poseen antes de introducir el concepto. "Esta explicación didáctica de lo que es una emoción la entiende hasta un niño de dos o tres años" (Núñez, 2005, p. 139).

En relación con el concepto de emoción, se presentó en el estudiantado una gran dificultad para definirlo. Cuando se les preguntó qué es una emoción, las niñas y los niños respondieron:

"No sé cómo decirlo", "hacer algo divertido", "no sé", "como cuando uno quiere una cosa y se emociona mucho para que se la traigan o algo que le pasa a uno", "algo como que no sé... algo que a uno le pasa y le da alegría y tristeza", "como sentirse bien o algo así", "un sentido a algo, a algo de uno, una emoción de uno, que uno quiere...no sé, algo así", "una emoción es lo que siente uno por dentro, diay, está triste, está feliz". "Hay diferentes tipos de emociones".

Pocos estudiantes lograron una aproximación conceptual sobre el significado de las emociones. En sus propias palabras:

"Son los sentimientos"; "es una palabra que refleja como los sentimientos de una persona"; "es una forma de actuar". 
Esto sugiere la necesidad de trabajar, explicar y enseñar el concepto de emoción (lo que es una emoción) con las niñas y los niños de este grupo, con el fin de que una vez que lo tengan claro, puedan identificar aquellas emociones que experimentan en su vida diaria.

\section{Emociones que conocen e identifican:}

La mayoría de niñas y niños mencionan la alegría, tristeza y enojo como las emociones que más conocen. Ninguno menciona el miedo. López, Traña y Araya (2005) señalan que las emociones más conocidas son ira, miedo, felicidad y tristeza. Únicamente un niño menciona el odio y una niña la depresión.

El estudiantado mostró poseer un pobre vocabulario emocional, lo cual es considerado por Bisquerra (2001) una limitación para tomar consciencia de las propias emociones y, por consiguiente, para controlarlas. Por ello se enfatiza en la importancia de potenciar el desarrollo del vocabulario emocional desde la escuela.

Con respecto al significado de las emociones, varios estudiantes manifestaron no conocer el significado de algunas emociones, tales como frustración y vergüenza. A continuación se describen algunos ejemplos:

Facilitadora: ¿Sabe usted qué es la frustración?

Niña 1: No.

Facilitadora: ¿Te has sentido frustrada?

Niña 2: No sé qué es eso.

Cuando se les solicita que definan emociones como enojo, felicidad, tristeza, vergüenza y otras, responden con ejemplos concretos mostrando dificultad para definir la emoción. Algunos de ellos son:

Facilitadora: ¿Qué es el enojo para usted?

Niña 1: El enojo es como... digamos yo me enojo, y me cae todo el mundo mal, entonces se pelea uno. Cuando uno está enojado empieza a criticar a las personas y eso.

Facilitadora: ¿Qué es la vergüenza?

Niña 2: La vergüenza es como ahorita en el acto cívico, que yo estaba allí y me daba vergüenza que todos me vieran. 
URL: http://www.una.ac.cr/educare

Facilitadora: ¿Qué es el enojo?

Niño 3: Pelearme con una persona que me molesta mucho.

Facilitadora: ¿Qué significa sentirse triste?

Niño 4: No sé, como llorar o algo así.

\section{Diferenciación de emociones:}

Algunos estudiantes presentan dificultades para diferenciar emociones, por ejemplo, el enojo y la decepción:

Facilitadora: ¿Sabes cuál es la diferencia entre estar enojado y decepcionado? ¿Hay alguna diferencia?

Niño 1: No, no sé.

Facilitadora: ¿Entonces hay alguna diferencia entre enojado y decepcionado?

Niño 2: No, es lo mismo yo creo que es lo mismo.

Facilitadora: ¿Sabe usted la diferencia entre estar enojada o decepcionada?

\section{Niña 3: No}

Facilitadora: ¿Te parece que es lo mismo?

Niña 3: Sí.

Un niño muestra confusión entre enojo y tristeza, cuando se le pregunta sobre qué es estar enojado y responde:

Niño: Estar bravo con alguien...es enojado, triste... no sé.

Otro grupo de estudiantes logra establecer la diferencia entre las emociones mencionadas.

Para lograr el conocimiento de las propias emociones, es importante que las niñas y los niños sepan distinguir entre una emoción y otra. Así, entonces, tener conciencia de ellas es la competencia emocional fundamental sobre la cual se construye el autocontrol. En la medida en que la persona logre distinguir las emociones que experimenta, podrá controlarlas y actuar para cambiarlas. 


\section{Manejo de las propias emociones en el grupo de estudiantes}

Durante el trabajo de campo se detectaron niñas y niños a los cuales se les dificultó manejar y controlar los propios estados emocionales. A continuación se describen algunos de estos casos:

Un niño manifestó durante la entrevista lo siguiente:

Facilitadora: Entonces, ¿Cuándo usted está enojado, qué hace?

Niño 1: Me le arrimo a la persona y le digo ¡qué es!, ¿quiere pleito? y me le‘abro’y le pego.

Facilitadora: Ahora... ¿Se acuerda de algún momento, en la escuela o en otro lugar, donde se ha sentido enojado?

Niño 1: En la escuela.

Facilitadora: ¿Y cuándo fue?

Niño 1: Mmm... hoy con un compañero, en mi aula.

Facilitadora: Ajá. ¿Y por qué se sintió enojado? ¿Qué sucedió?

Niño 1: El me pegó, y después yo vine y le pegué.

Una niña manifestó sentirse enojada cuando la insultan. Al respecto ella manifestó lo siguiente:

Niña 1: Me dan ganas de pegarle.

Facilitadora: Eso te provoca ganas de pegarle. ¿Pero qué has hecho en ese momento? ¿O qué has hecho cuando te has enojado, cuando te han insultado?

Niña 1: Yo también les digo cosas.

Facilitadora: ¿Qué cosas?

Niña 1: No sé... cosas feas.

En relación a cómo reaccionan las niñas y los niños cuando se enojan, expresaron lo siguiente:

Niño 1: Yo me aguanto; Niña 2. Yo también me aguanto; Niña 3: Ella me jala el pelo; Niña 4: Me voy al baño; Niña 5: Acuso si me molestan. 
URL: http://www.una.ac.cr/educare

Un niño expresó lo siguiente cuando se le preguntó sobre su reacción ante el enojo:

Facilitadora: ¿Qué hace usted cuando se enoja?

Niño1: Tiro chunches...

Facilitadora: ¿Le tira chunches a los demás? ¿Y qué pasa cuando hace eso?

Niño 1: Me pongo muy enojado.

Facilitadora: ¿Se pone muy enojado y qué?

Niño 1: Tiro las cosas.

En la clase se observó el enojo de un niño manifestado de la siguiente forma: El niño enojado hace señas con la mano al otro niño, golpeando su puño cerrado contra la palma de su mano en señal de advertencia indicándole que le va a pegar.

Es importante notar que la emoción del enojo es la reacción más frecuente con la que responden los niños y las niñas ante diferentes situaciones. De acuerdo con Bisquerra (2001), el enojo es una reacción de irritación que se genera cuando tenemos la sensación de haber sido perjudicados. La mayoría del estudiantado responde ante el enojo con agresión verbal y física, lo que este autor denomina agresión directa.

Dentro de las reacciones de los niños y niñas hacia el enojo se observaron pocas respuestas adecuadas, o algunos intentos de autocontrol, como por ejemplo:

Facilitadora: ¿Qué hiciste en ese momento, cuando experimentaste el enojo? ¿Cómo te comportaste?

Niña 1: Bueno, como le dije antes, yo le dije a mi mamá: porque eso no es justo"

Facilitadora: ¿Y con tu hermano, qué haces?

Niña 1: Yo le reclamo a él por qué dice eso, y me voy un ratito, y cuando me pasa vuelvo.

Según el citado autor, una respuesta no agresiva ante el enojo consiste en buscar actividades que le ayuden a calmarse, conversar con alguien al respecto, entre otras.

Una niña expresó su intento de autocontrolar su enojo. Cuando se le preguntó qué hace cuando se enoja ella respondió:

Diay, irme y dar la vuelta para tranquilizarme.

Para Goleman (1995), la manera en que manejemos nuestras emociones va a depender de nuestra inteligencia emocional. El autocontrol no implica negar o reprimir las emociones, 
implica crear un manejo que logre la expresión adecuada. De acuerdo con esto, el estudiantado observado trata de controlar su enojo, no completa el manejo adecuado de este, pues no busca la oportunidad de expresarlo de forma adecuada.

Analizando lo anterior desde la perspectiva de género, lo señalado por la mayoría de los varones en el cuestionario, en el grupo focal, en las entrevistas y en las observaciones, expresan que su reacción ante el enojo es la agresión física:

Facilitadora: ¿Cuando te enojas, ¿qué haces?

Niño 1: Si me patean, entonces yo me defiendo.

Niño 2: Busca a J., para pegarle. (Todos se ríen)

Niño 1: Pero él en este tiempo me quiere pegar a mí, ¿verdad?

Niño 2: Sí, porque usted me pateó cuando estábamos en el aula.

En una entrevista, un niño señala:

Facilitadora: ¿Cuando te enojas cómo te pones?

Niño 1: Muy enojado, a veces golpeo duro las paredes.

Facilitadora: ¿Cuánto tiempo te duró ese enojo?

Niño 1: Una semana.

Facilitadora: ¿Observaste alguna reacción en tu cuerpo? ¿Cómo estabas?

Niño 1: Yo... ah... temblando.

Facilitadora: ¿Cuando estás enojado tiemblas?

Niño 1: Sí.

Facilitadora: ¿Y tus manos?

Niño 1: Muy duras y empiezo a temblar y mi rostro arrugado.

Durante el estudio, se encontraron también algunas niñas que, aunque en menor frecuencia, manifiestan su enojo mediante agresión física, como se puede leer a continuación:

Niño 1: Ella le pega a todo el mundo (refiriéndose a una compañera que se encuentra cerca).

Niña 2: Sí, le jalo el pelo. 
Sin embargo, se encontró que, en su mayoría, las niñas reaccionan ante el enojo reprimiéndolo, gritando, insultando o llorando: "Trato de ocultar", "yo me aguanto", "me aíslo", "a veces pego gritos", "lloro o grito", "me quedo callada", "digo cosas...cosas feas".

Durante un recreo se observó a una niña sentada a un costado de la plaza de fútbol y al preguntarle si iba a jugar con sus compañeros, ella contestó: "Estaba jugando pero parecen unos... Uno me golpeó el brazo y me dio un bolazo por las nalgas". Entonces se le preguntó: ¿Qué hiciste? Ella responde: "Me vine a sentar aquí, son unos tontos".

En relación con lo anterior, se considera que la manera de reaccionar de estas niñas y niños está relacionada con los procesos de socialización, es decir, la manera que han sido educados según su sexo, en donde a los hombres se les ha permitido ser más agresivos para expresar sus emociones y reprimir algunas como el llanto; mientras que a las mujeres se les ha educado para ser más sumisas, reprimir conductas violentas para expresar emociones como la ira y expresar emociones a través del llanto.

En los resultados del cuestionario, respecto al manejo de otras emociones como la alegría, por ejemplo, algunos discentes señalan que cuando están felices "se les olvida todo" o "hacen sentir bien a los demás". Esto refleja un manejo inadecuado de dicha emoción porque, por una parte, debido a esta, olvidan sus responsabilidades. Por otro parte, "hacer sentir bien a los demás" no debería estar condicionado por la emoción que se experimente.

\section{Estrategias utilizadas por la maestra para la promoción del conocimiento y el manejo de las emociones de sus estudiantes en el salón de clases}

Las estrategias empleadas por la maestra en la clase para intervenir en el manejo de las emociones y resolución de conflictos, las conforman las advertencias sobre sanciones disciplinarias tales como boletas, expulsión o sacarlos de la clase, regaños y otros. Algunos ejemplos que describen lo anterior son:

Un niño patea a otro niño, la maestra interviene diciendo: "No haga eso, no se meta en problemas".

En otra situación la maestra interviene diciéndole a un niño: "No haga zancadillas, X se lo advierto, si usted hace eso se me va unos días a la casa. Ustedes saben que soy tolerante, pero no alcahueta".

En clase un niño hace cosas que buscan llamar la atención (canta, interrumpe, juega) la maestra enojada le expresa: "Me sale, si sigue en eso".

La maestra le expresa a un niño que no está trabajando en clase e interrumpe diciendo lo siguiente: "Deje de interrumpir o llamo de una vez a Doña X (su mamá). Saque algo y se pone a trabajar. Sino, ya usted sabe lo que viene" (boleta, expulsión). 
Durante la entrevista, la maestra expresó: “(...) ya me siento bien porque llego y ellos ya manejan las órdenes, la disciplina, ya como que se van comportando de manera adecuada, entonces ya como que la lección vuelve a ser más positiva".

La docente, en este caso, ha logrado el manejo de la disciplina mediante el uso de condicionamientos externos más que por estrategias que desarrollen habilidades de autocontrol. Sin embargo, es pertinente que la maestra favorezca la autorregulación, pues "(...) cuando las personas sienten que no tienen control sobre sus emociones experimentan una vivencia limitada y debilitante debido a que no pueden asumir la responsabilidad de sí mismos, sino que se la asignan a las emociones descontroladas y desorganizadas" (López y González, 2005 p. 23). De aquí, se rescata la importancia de trabajar estrategias para la regulación emocional con las niñas y los niños.

También se observó durante las clases que la maestra utiliza una serie de reforzadores positivos para promover la motivación en el estudiantado. En relación con lo anterior, la maestra manifestó durante la entrevista lo siguiente: "Yo...los felicito diciéndoles: lo hiciste muy bien, les doy un "sticker", les pongo sellos o cualquier cosa...".

De lo anteriormente expresado, se evidencia que la maestra promueve una motivación más de tipo extrínseca, que conduce al estudiante a que se comprometa en una actividad o realice una conducta por un incentivo o resultado anticipado, y no por una motivación intrínseca, la cual se refiere al deseo interno de la persona a comprometerse en una actividad sin mediar una recompensa o castigo. Con este comentario no se afirma que recurrir en determinado momento a estímulos externos sea negativo, pero tampoco es la manera más efectiva de promover la automotivación como una competencia de la inteligencia emocional.

Según Goleman (1995), la automotivación corresponde a aquellos impulsos emocionales que encausan a las personas a lograr metas establecidas. Esta habilidad incluye inspiración, perseverancia, confianza en uno mismo, capacidad de sobreponerse en la derrota y disfrutar el proceso de aprendizaje.

Durante las clases no se observó el uso de estrategias que permitieran manejar efectivamente los conflictos en el aula, o que propiciaran el desarrollo de habilidades en el estudiantado para la resolución de los mismos. Así por ejemplo, la maestra manifestó que los niños jugaban con una bola en la clase por lo que ella misma procedió a entregarla al conserje para que la guardara. Posteriormente, los niños van donde esta y le dicen que por error, la maestra se confundió y le dio la bola de ellos, de tal forma que lograron recuperarla. Al darse cuenta de la treta, la maestra interpela a los niños y les dice que mentir es deshonesto y que eso no se hace. Los hace disculparse con la conserje y les prohíbe traer bola a la escuela.

En la situación descrita, la maestra amonesta a los niños sin darles el espacio para la reflexión y la oportunidad de desarrollar habilidades tales como la empatía y la búsqueda de alternativas para solucionar el conflicto. Pues con esta actitud no deja claro al estudiantado que puede elegir otra alternativa, si su comportamiento es más adecuado, en vez de aplicar solamente un castigo. 
URL: http://www.una.ac.cr/educare

Se puede mencionar que la maestra ha realizado pequeños intentos por tratar de que los conflictos se resuelvan de la mejor manera, un ejemplo de lo anterior es señalado por una niña en el grupo focal, cuando menciona que para resolver un conflicto interpersonal, la maestra: "(...) nos lleva afuera y nos habla (...) y terminamos siendo amigos".

Sin embargo, a pesar de este esfuerzo por parte de la maestra, se evidenció una escasa formación por parte de la docente para facilitar a sus estudiantes estrategias que les propicien un adecuado desarrollo emocional. En relación con esto, Álvarez (2001) menciona que es claro que la novedad y la falta de tradición en la educación emocional sitúa a los educadores y las educadoras ante un reto al cual, en muchos casos, no se está preparado. Se necesita una formación en este campo. Es necesario tomar consciencia de que la única forma de abordar la educación emocional es mediante una consciente formación continua.

\section{Manejo de las emociones por parte de la maestra en el salón de clases}

Cuando se le pregunta a las niñas y a los niños, si la maestra les comunica sus emociones, algunos responden que no. Otros expresaron que a veces los comunica cuando está enojada. En relación con lo anterior se muestran algunos ejemplos:

Facilitadora: ¿La maestra les comunica sus emociones, es decir, cómo se siente ella?

Niño 1: A veces dice que ella está enojada.

Niño 2: O a veces dice que se siente mal que le duele la cabeza.

Niña 3: No.

Niño 4: No,...sí,... a veces.

Niño 5: ... ella viene feliz.

Niño 6: Ella viene feliz y sale triste porque nosotros hablamos mucho.

Niña 7: ...el primer día feliz y después triste.

Niño 8: ....siguió triste, sí....y triste,... triste.

Niña 9: Cuando está brava se queda de pie.

Niño 10: Manda boleta o recado.

Facilitadora: ¿Les explica por qué?, ¿Por qué está enojada o triste?

Niño 1: No. 
En algunos casos, a pesar de que la maestra no comunica verbalmente su emoción, esta es interpretada por sus estudiantes mediante la comunicación no verbal que ella expresa. En relación con lo anterior, la maestra señala:

Yo a veces siento más bien que el estado de ánimo que uno tiene ellos le dicen como se siente usted... Que sé yo, a veces viene uno como tenso o a veces viene uno como distraído y preocupado de otras cosas y llegan y le dicen a uno "hoy la vemos como preocupada". Como que ellos más bien perciben la actitud y depende de la actitud que uno tenga así ellos van a responder. Que sé yo, si uno a veces viene como muy tenso, responden como más tensos, si uno viene como mas relajado, trabajan como más relajado.

Es interesante notar que la maestra es consciente de que el estudiantado percibe su estado emocional. Incluso menciona que son los estudiantes quienes le evidencian el estado de ánimo que ella experimenta. Sin embargo, Begoña (2003) considera que educar con inteligencia emocional implica que el profesorado sepa identificar sus sentimientos y emociones, sepa controlar su expresión, no reprimirla sino ofrecer modelos adecuados de expresión sobre todo cuando se trata de emociones negativas que suelen ser más difíciles de comunicar de una forma respetuosa. De acuerdo con esto, sería recomendable que la maestra tome mayor consciencia de sus emociones, sin necesidad de que sean sus estudiantes quienes se las reflejen.

Con respecto a la manera de cómo refleja sus emociones negativas tales como el enojo, se pudo observar que en general utiliza el regaño y la amenaza de enviar boletas a los hogares o la expulsión como medidas disciplinarias. Durante una de las clases se observó la siguiente situación:

La maestra enojada le dice a un niño: "Yo no estaba bromeando cuando le dije que le bajaba la nota, si se volteaba".

En uno de los grupos focales, las alumnas y los alumnos mencionan que un compañero se enoja y grita en la clase. Cuando se les pregunta por la reacción de la maestra, ellos contestan: "Le manda boleta".

Durante la entrevista la maestra expresó que cuando ella se enoja:

(...) nada más los regaño, pero les hago ver que no es con el estudiante en sí, que me cae mal, tanto así, que el niño está al frente mío y no recibe ningún tipo de maltrato...Yo normalmente tiendo a quedarme más callada cuando me enojo porque aparte de las normas que uno ha tenido, uno no expresa mucho, a veces sí: me quedo como seria, viéndolos; pero ya ellos lo ven a uno serio, entonces ya ellos como que empiezan a reaccionar. 
Es importante recalcar que no se observaron gritos o insultos por parte de la maestra hacia las niñas y los niños, pero sí regaños con amenazas de castigos como los anteriormente señalados.

Según López y González (2005), el maestro debe dominar sus propias respuestas emocionales, ya que su conducta incide más en el comportamiento del estudiantado que los regaños y sermones. De allí lo importante de que la educadora logre expresar su enojo, sin necesidad de recurrir tanto a la amenaza de los castigos mencionados.

Por otro lado, es importante anotar que se observaron manifestaciones de afecto por parte de la maestra hacia sus estudiantes, como por ejemplo expresiones como, "mi amor" cuando se dirigía hacia algún discente. En cuanto a la habilidad de la empatía, la maestra manifiesta: "Chicos, ya les he dicho que trato de que nada me robe la paz, yo a veces trato de ponerme en el lugar de ustedes, pero yo ya tengo más años y no entiendo".

En esta oportunidad se puede observar cómo la docente procura tener empatía, es decir, ponerse en el lugar del estudiantado ante la situación presentada, sin embargo, es evidente la dificultad para lograrlo. De acuerdo con Begoña (2003), esta habilidad de empatía debe ser desarrollada en los docentes, al igual que su capacidad de escucha, con el fin de asumir una tarea más acertada en el desarrollo de la inteligencia emocional de sus estudiantes.

En relación con la expresión de emociones por parte de la maestra, esta señala que ella no es muy expresiva en el aula: "(...)yo no puedo manifestarme muy positiva porque entonces se hace un desorden, entonces tengo que andar más seria para que ellos entiendan que los límites se cumplen en el aula, ya en el recreo sí".

De lo anterior se percibe inseguridad por parte de la maestra para comunicar ciertas emociones y conductas en el aula, las cuales según ella podría interferir en el control, disciplina del grupo y el respeto hacia ella misma como docente. Comunicar supone manifestar actuaciones, pensamientos o sentimientos en situaciones interpersonales. Todo es comunicación, desde un gesto hasta una palabra.

Evidentemente en estas situaciones, la maestra muestra una forma no asertiva de comunicarse, porque no manifiesta al grupo lo que realmente ella siente en ese momento. Se puede considerar, entonces, que no está reflejando una madurez emocional. Para Begoña (2003), la persona docente debe ser capaz de modelar la adecuada expresión de sentimientos en relación con los alumnos y las alumnas, así como desarrollar conductas asertivas.

\section{El papel de la maestra en la promoción del conocimiento y manejo de las propias emociones del estudiantado de quinto grado}

De acuerdo con las observaciones realizadas en el salón de clases, las entrevistas y los grupos focales, se puede decir que la maestra de este estudio desempeña un papel de una docente tradicional, por cuanto mientras desarrolla la transmisión de los conocimientos de 
las materias básicas del currículo no aprovecha las oportunidades para potenciar la educación emocional del grupo discente de quinto grado escolar.

Con respecto a la organización de la experiencia de aprendizaje y la dinámica de trabajo que se promueve en el salón de clases, según las observaciones, quedó en evidencia que la maestra es quien la organiza, sin la participación activa del estudiantado, lo cual se explica a través de la asignación de tareas y la repetición mecánica de una serie de ejercicios o actividades, mientras los niños y las niñas esperan pasivamente a que se les indique, paso por paso, lo que deben hacer. Se visualiza la influencia de un enfoque pedagógico conductista.

En cuanto al papel tradicional en la transmisión de los conocimientos que ejerce la maestra se señalan algunos ejemplos acordes con las observaciones realizadas:

La maestra dicta una serie de problemas matemáticos a los niños y a las niñas. Estos copian en sus cuadernos. La maestra indica a los niños y a las niñas que deben resolverlos. Los estudiantes siguen las instrucciones y trabajan individualmente, no intercambian ideas entre ellos y ellas para resolver los ejercicios. Una vez concluidos los mismos, la maestra los revisa en forma individual y los resuelve en la pizarra. Posteriormente, escribe otros ejercicios en la pizarra y les da instrucciones a los niños y a las niñas de cómo deben resolverlos.

En relación con lo anterior, Begoña (2003) manifiesta que es importante que el profesorado comprenda que educar es mucho más importante que transmitir conocimientos. Para promover el desarrollo de la inteligencia emocional en el estudiantado, la persona docente debe desarrollar también su propia inteligencia emocional con el fin de poder ser un modelo para sus discentes. Se observó que la maestra durante su práctica pedagógica cotidiana no aprovecha las situaciones donde afloran los sentimientos de los niños y las niñas y no abre el espacio para trabajar la educación emocional.

Algunos ejemplos de lo anterior son:

Mientras en la clase los estudiantes y las estudiantes resolvían un ejercicio de matemáticas, uno de los niños manifestó a la maestra: "Usted nunca le pone atención”. La docente se molesta con el estudiante y le dice muy enojada: “Cómo se le ocurre decirme eso en semejante escándalo?" El niño intimidado responde: "Yo no dije eso". La maestra aún más enojada, le expresó: “¡No me diga eso, usted sabe que eso no es así!... ¿Cómo quiere que le ponga atención en semejante escándalo?". 
El pasaje anterior es una muestra de cómo la docente no le valida o le refleja el sentimiento al niño diciéndole por ejemplo: ¿Usted siente que no le presto atención? ¿Cómo te hace sentir esto?, y otras preguntas tendientes a favorecer la educación emocional. Es importante anotar que a pesar de que en la cotidianidad, podría presentarse muchos momentos de desorganización en el aula, en la medida en que se tome el tiempo para atenderlos, estos podrían disminuir y por otro lado contribuir a un incremento en el desarrollo emocional de las niñas y los niños.

En los grupos focales se les preguntó a las niñas y los niños lo siguiente: “ ¿Si alguno de ustedes está enojado o reacciona impulsivamente gritando, insultando, qué pasa, qué les dice la maestra?" Una niña señaló que: "nos regaña". Otro estudiante dijo: "nos lleva a que nos mande una boleta".

En la entrevista a la maestra, esta manifestó que el enojo debe ser manejado de manera adecuada y cuando se le interroga respecto a la expresión de enojo en los niños y las niñas, ella señala:

Yo siempre lo afirmo... uno puede expresar el enojo, pero no necesariamente tiene que agredir a las personas (...) y que el expresar (...) que el enojo es bueno y que es importante porque muchas veces uno hace cosas que posiblemente sin (él) no las hubiera podido hacer, le da como ese coraje como para salir adelante (...) y el enojo con uno mismo no es auto agredirse sino más bien obligarse a hacer las cosas, (...) uno enojado puede decir cosas, (...) uno no tiene que gritar ni patalear ni hacer berrinche para poder conseguir las cosas. A ellos también yo se los insisto, yo les he dicho: ante todo, el respeto y si ustedes quieren decir algo, se lo dicen con respeto a la persona, yo siento que hasta el momento va funcionando. No he visto así, como esos pleitos y esos golpes que a veces se dan en otros lugares; siento que los niños van como dándose el lugar, porque se está requiriendo el respeto.

La opinión de la docente con respecto al enojo muestra que debe haber una adecuada expresión de esta emoción; sin embargo, las observaciones y comentarios de los niños y las niñas manifiestan que los métodos más regulares para su manejo son el de la llamada de atención, regaño o boleta. El manejo que se le da a estas situaciones en el aula refleja que solo se trata de eliminar el sentimiento, sin una reflexión que guíe la expresión en una adecuada dirección. Educar con inteligencia emocional implica reconocer sus propias emociones y controlar su expresión, especialmente cuando algo no sale bien y la emoción que suele emerger es el enojo. Un esfuerzo de la docente por apoyar a sus estudiantes fue mencionado por una niña cuando expresó: "A veces habla con alguno y les pregunta que por qué está enojado o así". A pesar de que la maestra trata de que haya un reconocimiento de la emoción, se queda en el sentimiento y no brinda las estrategias para expresarlo de forma adecuada.

Por otro lado, respecto a otra expresión de sentimientos, cuando se le preguntó a la maestra sobre cuál es su reacción cuando nota un niño triste en el aula, ella respondió: 
Yo lo dejo trabajando normalmente y cuando yo ya tengo un espacio con él, lo llamo por aparte y le pido que si quiere comentarme, que puede tener la confianza de decirme las cosas. Yo lo escucho, pero si él no quiere, yo no lo obligo o si está llorando yo lo dejo hasta que él tenga la confianza para hacerlo.

Este manejo de la docente se evidencia y refuerza con el comentario de un niño durante uno de los grupos focales mientras se hablaba de cuando se expresan sentimientos en la clase:

Facilitadora: Hummm...no se puede gritar en la clase. Pero bueno, hay otras formas de expresar sentimientos que no sea gritando.

Niño 1: ¡Llorando!

Facilitadora: ¿Llorando? ¿Está prohibido?

Niño1: No

Facilitadora: ¿Se puede llorar en la clase?

Niño 2: Sí, pero lo mandan para afuera.

Una vez más se refleja la necesidad de que la educadora cuente con estrategias para desarrollar un proceso de alfabetización emocional en el estudiantado. En la entrevista con la maestra, ella reafirma esta necesidad de conocer estrategias para desarrollar la inteligencia emocional. Cuando se le pregunta si hay momentos en el aula cuando las niñas y los niños puedan expresar sentimientos, ella manifiesta:

Como estrategia no, tal vez no plantearlo como una estrategia porque a veces uno puede planear una cosa, pero le sale otra y muchas veces uno planea...que sé yo, si pudiera, no sé, hacer una comparación: planear una dinámica y en vez de hacer una dinámica lo que le sale es una grosería.

Lo anterior nos indica que el desarrollo emocional de los niños y las niñas de esta microcultura en particular no constituye un objetivo consciente de la tarea formadora de esta docente. Al respecto, Begoña (2003) sugiere que los grupos de docentes deberían ser capaces de utilizar la metodología de la planificación en función de metas y resolución de problemas. Esta promoción del maestro y la maestra del conocimiento y manejo de las propias emociones de los discentes y las discentes facilitaría la creación de ambientes positivos de aprendizaje. 
URL: http://www.una.ac.cr/educare

\section{Consideraciones finales}

Las principales conclusiones que se obtuvieron de la presente investigación:

- En cuanto al manejo de las propias emociones, la mayoría del estudiantado señaló que una de las emociones más fuertes que experimentan es el enojo, la cual es la que más propicia la pérdida del autocontrol. Esto interfiere negativamente en sus relaciones con los demás y provoca dificultades en el ambiente de aula.

- Desde una perspectiva de género, se encontró que la mayoría de los varones expresan su reacción ante el enojo con agresión física, mientras que las mujeres tienden a reprimir sus emociones, quedándose calladas o llorando sin expresarse asertivamente. Este resultado se asocia con los procesos de socialización, es decir, la manera en que han sido educados según su sexo, en donde a los hombres se les ha permitido ser más agresivos para expresar sus emociones, mientras que a las mujeres se les ha educado para ser más sumisas y reprimir más sus emociones.

- La maestra mostró algunas dificultades para expresar asertivamente sus emociones al estudiantado, con lo cual afectó el modelaje hacia la gestión adecuada de las emociones.

- La docente de este estudio cumple un papel tradicional como docente, centrándose mayormente en la transmisión de conocimientos de las materias básicas del currículo, y dejando de lado la educación emocional del estudiantado durante las lecciones. A pesar de que esta se muestra receptiva al aprendizaje emocional, no utiliza estrategias adecuadas de intervención en la dinámica de la clase para promover el desarrollo de habilidades que favorezcan la inteligencia emocional. Estos resultados se asocian con la escasa formación de la docente en el campo de la educación emocional.

- Es importante incorporar la educación emocional dentro del currículo escolar para lograr el pleno desarrollo de la personalidad, lo que implica que el desarrollo cognitivo sea complementado con el desarrollo emocional. El papel del personal docente en este proceso es fundamental, por lo que se hace necesaria su capacitación y promover que trabaje su propia inteligencia emocional, ya que constituye un modelo para el estudiantado, pues le enseña a controlar y gestionar sus emociones a través de su propia práctica pedagógica.

\section{Referencias}

Álvarez, M. (Coord.). (2001). Diseño y evaluación de programas de educación emocional (2a ed.). España: Praxis.

Begoña, I. (2003). Dirigir y educar con inteligencia emocional. smProfes.net. Recuperado de http://www.profes.net/rep_documentos/Noticias/IntelEmoc.pdf

Bisquerra, R. (2001). Educación emocional y bienestar. España: Praxis. 
Bisquerra, R. (2002). La competencia emocional. En M. Álvarez y R. Bisquerra (Coords.), Manual de orientación y tutoría (pp. 144/69-144/83). España: Praxis.

Casas, G. (2001). La inteligencia emocional. (Conferencia). Recuperado de www.binasss.sa.cr/ bibliotecas/bhp/inteligencia1.doc

Colom, R. B. (1998). Capacidades humanas. España: Pirámide.

Cortese, A. (s.f). Competencias emocionales. Recuperado de http://www.inteligencia-emocional. org/articulos/competenciasemocionales.htm

Goleman, D. (1995). Inteligencia emocional. México: Javier Vergara Editor.

López, K., Traña, M. y Araya, S. (2005). Fortaleciendo mis emociones positivas y potenciando mi desarrollo humano: Una propuesta metodológica desde el trabajo social con adolescentes de educación secundaria (el caso de los/las estudiantes de octavo año del Colegio Gregorio Ramírez de Alajuela). (Tesis de licenciatura). Escuela de Trabajo Social. Sede del Occidente, Universidad de Costa Rica. San José Costa Rica.

López, M. E. y González, M. F. (2005). Inteligencia emocional. (Tomo I, 6a reimpresión). Colombia: Gamma.

Núñez, M. (2005). El crecimiento emocional social en psicopedagogía. Caracas: Torino.

Portugá, S. y Cruz, E. (1999). Inteligencia emocional. México: Universidad Virtual del Sistema Tecnológico Monterrey.

Rizo, W. (1997). De regreso a casa. Colombia: Norma.

Rodríguez, G., Gil, J. y García, E. (1996). Metodología de la investigación cualitativa (2a ed.). España: ALJIBE.

Taylor, S. J. y Bodgan, R. (1992). Introducción a los métodos cualitativos de investigación. Argentina: Paidós.

Zabala, A. y Arnau, L. (2007) 11 ideas clave. Cómo aprender y enseñar competencias. Barcelona: Graó.

\section{Cómo citar este artículo, según APA:}

Villanueva, R. y Valenciano, G. (2012). El papel de la maestra en la promoción de dos competencias de la inteligencia emocional de niñas y niños de quinto grado. Revista Electrónica Educare, 16(3), 49-75. Consultado de http://www.revistas.una.ac.cr/index.php/EDUCARE/issue/current

Nota: Para citar este artículo en otros sistemas puede consultar el hipervínculo "Como citar el artículo" en la barra derecha de nuestro sitio web:

http://www.revistas.una.ac.cr/index.php/EDUCARE/index 